\title{
An odontometric study of the maxillary molars in Australian marsupials. - I. The koala (Phascolarctos cinereus)
}

\author{
By
Ryuji UENO $^{1,3,5}$, Akira IIMURA ${ }^{2}$, Shunji YOSHIDA ${ }^{3}$, Kenji KONDO ${ }^{1}$, Iwao SATO ${ }^{3}$, Maciej HENNEBERG ${ }^{4}$ and Grant C. TOWNSEND ${ }^{5}$ \\ ${ }^{1}$ Department of Dental Technology, The Nippon Dental University College at Tokyo, \\ 2-3-16 Fujimi, Chiyoda-ku, Tokyo 102-0071, Japan \\ ${ }^{2}$ Department of Anatomy, Kanagawa Dental College, 82 Inaoka-cho, Yokosuka-shi, Kanagawa 238-8580, Japan \\ ${ }^{3}$ Department of Anatomy, School of Life Dentistry at Tokyo, The Nippon Dental University, \\ 1-9-20 Fujimi, Chiyoda-ku, Tokyo 102-8159, Japan \\ ${ }^{4}$ Discipline of Anatomical Sciences, School of Medical Sciences, The University of Adelaide, \\ Medical School North Building, Frome Road, SA 5005, Australia \\ ${ }^{5}$ School of Dentistry, The University of Adelaide, 233 North Terrace, SA 5005, Australia
}

-Received for Publication, January 20, 2010-

Key Words: odontometry, molar crown dimensions, dentition, koala, masticatory function

\begin{abstract}
Summary: Crown dimensions of the maxillary molars were measured in the koala (Phascolarctos cinereus). There were no significant differences in crown diameters between the first and second molars, however the fourth molars were reduced in all crown diameters. The third molar was smaller than the first or second molars in buccolingual crown diameters but there were no significant differences in mesiodistal crown diameters. It is proposed that the similar shapes of the first and second molars are associated with similar types of masticatory activity involving these teeth, The shape of the third molar, which is reduced in size buccolingually, may be linked to the koala's occlusal function which is characterized by a condylar action that leads to differences in movement between opposing anterior and posterior molar teeth during the occlusal stroke. The fourth molar, the smallest of the molar teeth in crown diameter, erupts significantly later than the other molars, and its reduction may be explained by the terminal and distal reduction theories. It is proposed that the pattern of molar morphology in the koala is associated with both masticatory activity linked to its characteristic occlusal function, as well as reflecting the sequence of tooth emergence.
\end{abstract}

\section{Introduction}

It is accepted widely that the dental morphology of mammals is closely related to their masticatory function and feeding habits ${ }^{1)}$. There have been many general descriptions of the teeth of mammals and morphological differences have been observed even within the same species $^{2}$. Within the molar series, variations in number, form and size of teeth have been reported in many mammalian species ${ }^{3-9)}$. Although some explanations and hypotheses relating to these variations have been proposed $^{10-15)}$, the patterns of molar morphology vary in different species of mammals, including humans ${ }^{3,5,16}$, so additional investigations of mammalian dentitions that have not yet been described are still needed.

The koala is a specialized folivore and its diet is restricted to eucalyptus leaves. This specialization is reflected in a high degree of adaptation in dental crown morphology and jaw movement ${ }^{17,18}$. Therefore, this animal provides a good model to investigate morphological changes in the dentition and to explore the relationship between form and function.

The aim of this study was to quantitatively describe morphological differences within the maxillary molars of the koala, from the first to the fourth molar, to determine whether there were any trends or relationships evident within or between these teeth and to interpret the findings in the light of current knowledge about mammalian molar morphology.

Corresponding author: Ryuji Ueno, Department of Dental Technology, The Nippon Dental University College at Tokyo, 2-3-16 Fujimi, Chiyodaku, Tokyo 102-0071, Japan. E-mail: r-ueno@tandai.ndu.ac.jp 


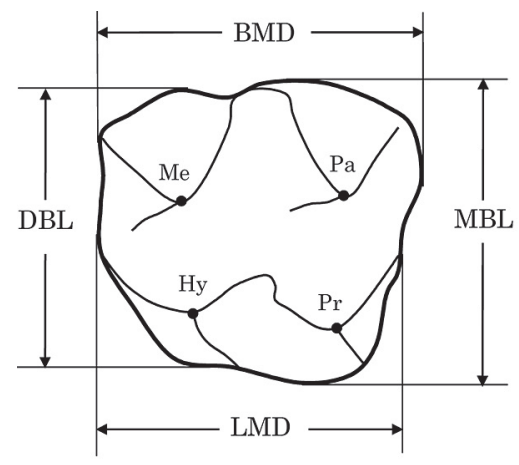

$1 \mathrm{~B}$

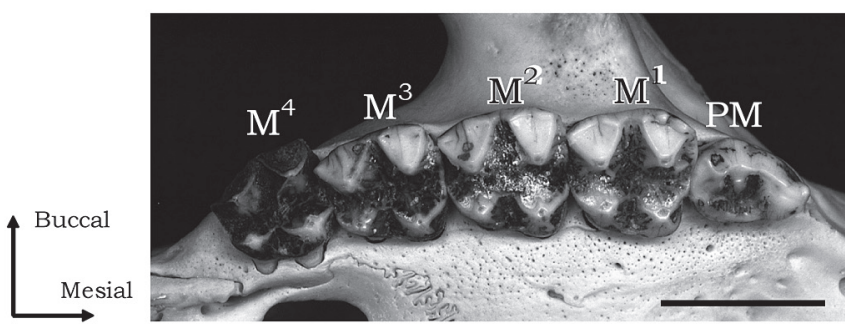

$1 \mathrm{~A}$

Fig. 1. Photograph(A) of maxillary right molars and schematic illustration(B) of the measurement of crown dimensions of the maxillary right first molar in the koala (scale bar $=10 \mathrm{~mm}$ ). $\mathrm{PM}$, premolar; $\mathrm{M}^{1}$, first molar; $\mathrm{M}^{2}$, second molar; $\mathrm{M}^{3}$, third molar; $\mathrm{M}^{4}$, fourth molar; Pr, protocone; $\mathrm{Pa}$, paracone; Hy, hypocone; Me, metacone; BMD, buccal mesiodistal diameter; LMD, lingual mesiodistal diameter; MBL, mesial buccolingual diameter; DBL, distal buccolingual diameter.

\section{Materials and Methods}

A sample of 14 dry koala skulls (8 males and 6 females) housed in the Discipline of Anatomical Sciences at The University of Adelaide, Adelaide, South Australia, Australia, was examined. These specimens were selected as they displayed no loss of teeth and very little wear on occluding dental surfaces.

Maxillary right molar crown dimensions, including buccal and lingual mesiodistal diameters (BMD, LMD) and mesial and distal buccolingual diameters (MBL, DBL) were measured to the nearest $0.01 \mathrm{~mm}$ using digital sliding calipers (Mitsutoyo Co., Japan) with specially pointed beaks (Fig. 1). Each tooth was measured three times by one observer (R.U.) and the average of the three readings was taken as the diameter for that tooth. Some dental crown indices including length-breadth indices $(\mathrm{MBL} / \mathrm{BMD} \times 100, \mathrm{DBL} / \mathrm{LMD} \times 100)$, mesiodistal diameter index $(\mathrm{LMD} / \mathrm{BMD} \times 100)$, buccolingual diameter index $(\mathrm{MBL} / \mathrm{DBL} \times 100)$, and the crown module $((\mathrm{BMD}$ $+\mathrm{LMD}+\mathrm{MBL}+\mathrm{DBL}) / 4$ ) were calculated for the four maxillary right molar teeth. The size reduction of molar teeth was analyzed according to the reduction index described by Fujita ${ }^{19}$. Descriptive statistics, including mean values, standard deviations (SD) and coefficients of variation $(\mathrm{CV})$ were calculated using Statcel 2 (OMS Publishing Inc., Ver. 2, Japan) on a personal computer. Differences between measurements were analyzed using Student's t-test, as well as Mann-Whitney's U-test and Wilcoxon's signed-ranks test. The probability level for statistical significance was set as $\mathrm{p}<0.05$.

\section{Results}

Table 1 shows mean values, standard deviations (SD), coefficients of variation $(\mathrm{CV})$ and crown indices for the maxillary molar crown diameters of the koala and the results of $\mathrm{t}$-tests between the maxillary molars. There were no significant differences in crown diameters between the first and second molars. The fourth molar was smaller overall than the other molars in both sexes. The first molar showed almost the same value as the other molars in $\mathrm{LMD} / \mathrm{BMD}$, but was larger than the other molars in DBL/LMD. In comparison, the value of the CV for the first molar was smallest, indicating that it showed the least relative variability in size. For all the molars, the values of the ratio MBL/DBL were over 109.

Table 2 displays the crown diameters that showed significant differences between males and females. The female fourth molar was smaller than the male fourth molar in every crown diameter and also in the crown module. No significant differences in crown indices were noted between males and females. Table 3 shows the reduction index (RI) statistics for the second to fourth molars. The third and fourth molars were reduced in all crown diameters, as well as in the crown module, in both sexes, while the second molar in females was larger except for the DBL dimension.

Figure 2 provides a schematic representation of the outlines of the maxillary molar crowns. The buccolingual crown diameter of the third molar was smaller than first and second molars and the fourth molar was smaller in buccolingual and mesiodistal crown diameters than the other molars. 
Table 1-1. Maxillary molar crown diameter and indices in the male koala

\begin{tabular}{|c|c|c|c|c|c|c|c|c|c|c|c|c|c|c|c|c|c|c|c|c|c|c|}
\hline & \multicolumn{4}{|c|}{$\mathrm{M}^{1}$} & \multicolumn{4}{|c|}{$\mathrm{M}^{2}$} & \multicolumn{4}{|c|}{$\mathrm{M}^{3}$} & \multicolumn{4}{|c|}{$\mathrm{M}^{4}$} & \multicolumn{6}{|c|}{ significant differences } \\
\hline & $\mathrm{N}$ & Mean & $\mathrm{SD}$ & $\mathrm{CV}$ & $\mathrm{N}$ & Mean & $\mathrm{SD}$ & $\mathrm{CV}$ & $\mathrm{N}$ & Mean & $\mathrm{SD}$ & $\mathrm{CV}$ & $\mathrm{N}$ & Mean & SD & $\mathrm{CV}$ & $\mathrm{M}^{1}-\mathrm{M}^{2}$ & $\mathrm{M}^{1}-\mathrm{M}^{3}$ & $\mathrm{M}^{1}-\mathrm{M}^{4}$ & $\mathrm{M}^{2}-\mathrm{M}^{3}$ & $\mathrm{M}^{2}-\mathrm{M}^{4}$ & $M^{3}-M^{4}$ \\
\hline BMD & 8 & 7.97 & 0.39 & 4.89 & 8 & 7.93 & 0.21 & 2.65 & 8 & 7.92 & 0.39 & 4.92 & 8 & 7.39 & 0.33 & 4.47 & NS & NS & $*$ & NS & $*$ & $*$ \\
\hline MBL & 8 & 8.02 & 0.31 & 3.87 & 8 & 8.09 & 0.35 & 4.33 & 8 & 7.54 & 0.33 & 4.38 & 8 & 6.67 & 0.29 & 4.35 & NS & $*$ & $*$ & * & $*$ & $*$ \\
\hline DBL & 8 & 7.31 & 0.25 & 3.42 & 8 & 7.14 & 0.30 & 4.20 & 8 & 6.52 & 0.19 & 2.91 & 8 & 5.60 & 0.25 & 4.46 & NS & $*$ & $*$ & * & * & * \\
\hline crown module & 8 & 7.71 & 0.28 & 3.60 & 8 & 7.68 & 0.28 & 3.64 & 8 & 7.36 & 0.24 & 3.29 & 8 & 6.63 & 0.24 & 3.60 & NS & $*$ & $*$ & $*$ & $*$ & $*$ \\
\hline $\mathrm{MBL} / \mathrm{DBL}$ & 8 & 109.77 & 2.06 & 1.87 & 8 & 113.29 & 1.73 & 1.53 & 8 & 115.64 & 4.72 & 4.08 & 8 & 119.25 & 2.77 & 2.32 & $*$ & $*$ & $*$ & NS & * & NS \\
\hline MBL/BMD & 8 & 100.70 & 3.28 & 3.26 & 8 & 101.98 & 2.61 & 2.56 & 8 & 95.24 & 3.84 & 4.03 & 8 & 90.36 & 3.95 & 4.38 & NS & $*$ & $*$ & $*$ & $*$ & $*$ \\
\hline DBL/LMD & 8 & 97.07 & 2.06 & 2.12 & 8 & 94.21 & 1.64 & 1.74 & 8 & 87.22 & 3.46 & 3.96 & 8 & 81.60 & 3.47 & 4.25 & $*$ & $*$ & $*$ & * & * & * \\
\hline
\end{tabular}

Table 1-2. Maxillary molar crown diameter and indices in the female koala

\begin{tabular}{|c|c|c|c|c|c|c|c|c|c|c|c|c|c|c|c|c|c|c|c|c|c|c|}
\hline & \multicolumn{4}{|c|}{$\mathrm{M}^{1}$} & \multicolumn{4}{|c|}{$\mathrm{M}^{2}$} & \multicolumn{4}{|c|}{$\mathrm{M}^{3}$} & \multicolumn{4}{|c|}{$\mathrm{M}^{4}$} & \multicolumn{6}{|c|}{ significant differences } \\
\hline & $\mathrm{N}$ & Mean & $\mathrm{SD}$ & $\mathrm{CV}$ & $\mathrm{N}$ & Mean & $\mathrm{SD}$ & $\mathrm{CV}$ & $\mathrm{N}$ & Mean & SD & $\mathrm{CV}$ & $\mathrm{N}$ & Mean & SD & $\mathrm{CV}$ & $\mathrm{M}^{1}-\mathrm{M}^{2}$ & $\mathrm{M}^{1}-\mathrm{M}^{3}$ & $\mathrm{M}^{1}-\mathrm{M}^{4}$ & $\mathrm{M}^{2}-\mathrm{M}^{3}$ & $\mathrm{M}^{2}-\mathrm{M}^{4}$ & $\mathrm{M}^{3}-\mathrm{M}^{4}$ \\
\hline BMD & 6 & 7.69 & 0.11 & 1.43 & 6 & 7.80 & 0.15 & 1.92 & 6 & 7.51 & 0.25 & 3.33 & 6 & 6.92 & 0.20 & 2.89 & NS & NS & $*$ & $*$ & $*$ & $*$ \\
\hline MBL & 6 & 7.74 & 0.09 & 1.16 & 6 & 7.91 & 0.09 & 1.14 & 6 & 7.39 & 0.07 & 0.95 & 6 & 6.29 & 0.12 & 1.91 & NS & $*$ & $*$ & $*$ & $*$ & $*$ \\
\hline DBL & 6 & 7.04 & 0.19 & 2.70 & 6 & 6.91 & 0.36 & 5.21 & 6 & 6.31 & 0.19 & 3.01 & 6 & 5.29 & 0.26 & 4.91 & NS & $*$ & $*$ & $*$ & $*$ & * \\
\hline crown module & 6 & 7.39 & 0.09 & 1.26 & 6 & 7.44 & 0.15 & 2.00 & 6 & 7.07 & 0.13 & 1.85 & 6 & 6.25 & 0.14 & 2.28 & NS & $*$ & $*$ & $*$ & $*$ & $*$ \\
\hline MBL/DBL & 6 & 110.02 & 3.51 & 3.19 & 6 & 114.62 & 5.99 & 5.23 & 6 & 117.19 & 3.21 & 2.74 & 6 & 119.30 & 6.14 & 5.15 & NS & $*$ & $*$ & NS & NS & NS \\
\hline MBL/BMD & 6 & 100.67 & 1.84 & 1.83 & 6 & 101.35 & 1.75 & 1.73 & 6 & 98.49 & 3.05 & 3.10 & 6 & 90.95 & 1.40 & 1.54 & NS & NS & $*$ & NS & $*$ & $*$ \\
\hline DBL/LMD & 6 & 99.12 & 1.34 & 1.36 & 6 & 96.50 & 3.17 & 3.29 & 6 & 89.64 & 2.13 & 2.38 & 6 & 81.32 & 3.40 & 4.18 & NS & $*$ & $*$ & $*$ & * & * \\
\hline
\end{tabular}

*: $\mathrm{P}<0.05$, NS: not significant

Table 2. Significant differences of maxillary molar crown diameter and indices between the male and female koala

\begin{tabular}{lcccc}
\hline & $\mathrm{M}^{1}$ & $\mathrm{M}^{2}$ & $\mathrm{M}^{3}$ & $\mathrm{M}^{4}$ \\
\hline BMD & $\mathrm{NS}$ & $\mathrm{NS}$ & $*$ & $*$ \\
LMD & $*$ & $*$ & $*$ & $*$ \\
MBL & $\mathrm{NS}$ & $\mathrm{NS}$ & $\mathrm{NS}$ & $*$ \\
DBL & $*$ & $\mathrm{NS}$ & $\mathrm{NS}$ & $*$ \\
crown module & $*$ & $\mathrm{NS}$ & $*$ & $*$ \\
LMD/BMD & $\mathrm{NS}$ & $\mathrm{NS}$ & $\mathrm{NS}$ & $\mathrm{NS}$ \\
MBL/DBL & $\mathrm{NS}$ & $\mathrm{NS}$ & $\mathrm{NS}$ & $\mathrm{NS}$ \\
MBL/BMD & $\mathrm{NS}$ & $\mathrm{NS}$ & $\mathrm{NS}$ & $\mathrm{NS}$ \\
DBL/LMD & $\mathrm{NS}$ & $\mathrm{NS}$ & $\mathrm{NS}$ & $\mathrm{NS}$ \\
\hline
\end{tabular}

*: $\mathrm{P}<0.05$, NS: not significant

\section{Discussion}

Although many studies have been published on mammalian maxillary molar morphology, including in humans, little is known about the dentition of the koala. In the present study, the fourth molar was found to be smaller overall than the other molars and the third and fourth molars were reduced in all crown diameters and also in the crown module. In addition, according to the $\mathrm{MBL} / \mathrm{DBL}$ values, in all molars the mesial buccolingual crown diameter was larger than the distal buccolingual crown diameter by $9-19 \%$. Although the first and second molars were similar in mesiodistal and buccolingual size, our findings are generally consistent with the terminal and distal reduction theories that were put forward originally by Bolk ${ }^{20)}$ and Fujita ${ }^{21)}$, with later-forming and more distal molars in the dental arch tending to show more reduction in size than earlier-developing more mesially placed molars.

Some explanations and hypotheses have been published previously to explain the pattern of variability in crown morphology observed along the mammalian molar series. For example, Butler ${ }^{10)}$ hypothesized that the forms of teeth are influenced by morphogenetic fields with the position of each tooth within a particular field showing a graded expression of features according to its location. Sofaer ${ }^{12)}$ noted that later-developing teeth are more likely to be restricted for space and tend to be smaller than earlier-developing members of the same class. Gingerich ${ }^{14)}$ stated that a central tooth in the tooth row should be the best integrated functionally, and thus the least variable. In the koala, the eruption sequence of the molars occurs from the first to the fourth ${ }^{22)}$. In spite of their eruption order, in this study the first and second molars showed almost the same values for buccolingual and mesiodistal crown diameters. Gingerich and Shoeninger ${ }^{15)}$ proposed variability is related to occlusal complexity and in indriids the second molars were found to be consistently less variable than first molars even though they tend to develop and erupt later. The extent of tooth wear of maxillary molars in the koala was recorded and assigned to tooth wear classes based on Martin ${ }^{23)}$, and the extent of wear was similar on the first two mo- 
Table 3-1. Reduction indices of the crown dimensions of $\mathrm{M}^{2}$ to $\mathrm{M}^{4}(\%)$ in the male koala

\begin{tabular}{|c|c|c|c|c|c|c|c|c|c|c|c|c|}
\hline & \multicolumn{4}{|c|}{$\mathrm{M}^{2}$} & \multicolumn{4}{|c|}{$\mathrm{M}^{3}$} & \multicolumn{4}{|c|}{$\mathrm{M}^{4}$} \\
\hline & $\mathrm{N}$ & Mean & $\mathrm{SD}$ & $\mathrm{CV}$ & $\mathrm{N}$ & Mean & $\mathrm{SD}$ & $\mathrm{CV}$ & $\mathrm{N}$ & Mean & $\mathrm{SD}$ & $\mathrm{CV}$ \\
\hline BMD & 8 & 99.60 & 3.73 & 3.74 & 8 & 99.54 & 6.11 & 6.14 & 8 & 92.79 & 3.31 & 3.57 \\
\hline LMD & 8 & 100.66 & 1.58 & 1.57 & 8 & 99.38 & 1.68 & 1.69 & 8 & 91.21 & 3.40 & 3.73 \\
\hline MBL & 8 & 100.83 & 0.72 & 0.71 & 8 & 93.98 & 1.02 & 1.09 & 8 & 83.25 & 3.28 & 3.94 \\
\hline DBL & 8 & 97.70 & 1.57 & 1.60 & 8 & 89.27 & 2.01 & 2.26 & 8 & 76.62 & 2.55 & 3.32 \\
\hline crown module & 8 & 99.71 & 0.94 & 0.94 & 8 & 95.60 & 1.83 & 1.91 & 8 & 86.08 & 2.27 & 2.64 \\
\hline
\end{tabular}

Table 3-2. Reduction indices of the crown dimensions of $\mathrm{M}^{2}$ to $\mathrm{M}^{4}(\%)$ in the female koala

\begin{tabular}{|c|c|c|c|c|c|c|c|c|c|c|c|c|}
\hline & \multicolumn{4}{|c|}{$\mathrm{M}^{2}$} & \multicolumn{4}{|c|}{$\mathrm{M}^{3}$} & \multicolumn{4}{|c|}{$\mathrm{M}^{4}$} \\
\hline & $\mathrm{N}$ & Mean & SD & $\mathrm{CV}$ & $\mathrm{N}$ & Mean & $\mathrm{SD}$ & $\mathrm{CV}$ & $\mathrm{N}$ & Mean & $\mathrm{SD}$ & $\mathrm{CV}$ \\
\hline BMD & 6 & 101.44 & 0.81 & 0.80 & 6 & 97.69 & 2.14 & 2.19 & 6 & 90.01 & 2.81 & 3.13 \\
\hline LMD & 6 & 100.81 & 1.19 & 1.18 & 6 & 99.19 & 2.03 & 2.05 & 6 & 91.54 & 2.35 & 2.57 \\
\hline MBL & 6 & 102.14 & 1.62 & 1.59 & 6 & 95.55 & 1.88 & 1.97 & 6 & 81.33 & 2.39 & 2.94 \\
\hline DBL & 6 & 98.16 & 3.60 & 3.67 & 6 & 89.70 & 1.86 & 2.07 & 6 & 75.13 & 4.16 & 5.54 \\
\hline crown module & 6 & 100.69 & 1.02 & 1.01 & 6 & 95.59 & 1.27 & 1.33 & 6 & 84.55 & 2.11 & 2.49 \\
\hline
\end{tabular}

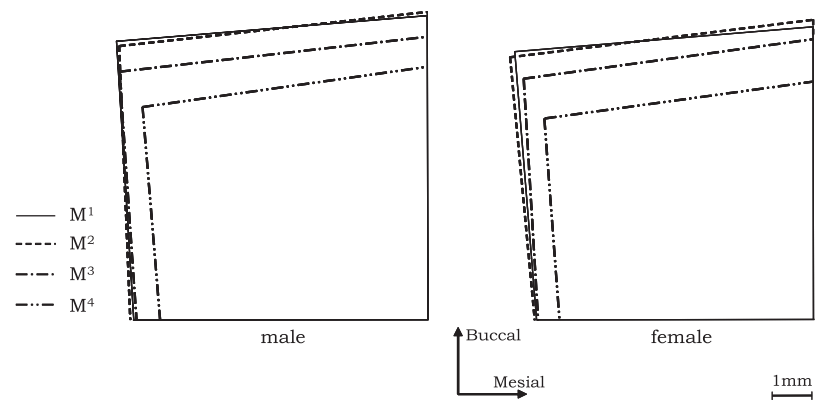

Fig. 2. ESchematic representation of the crown dimensions of the maxillary molars in the koala.

lars. It is suggested that the lack of significant differences in crown diameters between the first and second molars may reflect similar levels of masticatory activity associated with these two teeth.

Lanyon and Sanson ${ }^{17)}$ observed occlusal relationships of the koala by videoradiography and explained that the ipsilateral condyle acts as a fixed hinge, where the centre of rotation of horizontal mandibular movement lies within the ipsilateral condyle head on the active side and ipsilateral hinging is maintained throughout the occlusal stroke. As the arc of the lower jaw moves, the more anterior teeth move considerably further than the posterior molars during occlusal function, with the posterior molars sequentially entering occlusion before the anterior molars. This arc is reflected in dental arch width in the molar region, with the inter-molar distance being wider in the region of the anterior molars than the posterior molars. Although these authors did not describe the detail of differences in buccolingual crown diameters between molar teeth, the smaller buccolingual crown diameter of the third molar may be linked to differences in occlusal function along the molar row. Macho ${ }^{24)}$ noted that not all the results from morphometric studies of the dentition can be entirely explained by the field theory or the hypotheses of environmental constraints on later developing teeth. In the koala, it is suggested that masticatory activity and the characteristic occlusion of the koala are associated with their molar morphology, in addition to the influence of eruption order.

\section{Acknowledgments}

This work was supported by Grant-in-Aid for Scientific Research (C) 16590156.

\section{References}

1) Lucas PW. Tooth shape. In: Lucas P W, Dental functional morphology How teeth work Cambridge, Cambridge University Press, 2004; 87-132.

2) Hillson S. Size and shape. In: Hillson S, Teeth Cambridge, Cambridge University Press, 1986; 231-282.

3) Mahler PE. Molar size sequence in the great apes: Gorilla, Orangutan and Chimpanzee. J Dent Res 1980; 59:749-752.

4) Yamamoto T. A comparative morphological study of tooth in Racoon dogs. J Kyushu Dent Soc 1983; 37:1-29 (in Japanese).

5) Takada S. Molar size sequence in seven species of Cercopithecidae. Aichi-Gakuin J Dent Sci 1989; 27:925-964.

6) Kondo S, Hanamura $\mathrm{H}$ and Wakatsuki E. Comparison of the crown dimensions between the maxillary fourth deciduous premolar and the first molar in Tupaia glis. J Showa Univ Dent Soc 1993; 13:22-26.

7) Kondo S, Hanamura $\mathrm{H}$ and Wakatsuki E. Crown dimensions of the maxillary molars in Tupaia glis; Okajimas Folia Anat Jpn 1994; 70:261-266.

8) Kondo S, Hanamura $\mathrm{H}$, Natori $\mathrm{M}$ and Wakatsuki E. Crown structure of the maxillary molars in the Japanese shrew mole, 
Urotrichus talpoides (Insectivora, Talpidae). Okajimas Folia Anat Jpn 1998; 74:237-242.

9) Natsume A, Koyasu K, Oda S, Nakagaki H, Kawai T and Hanamura $\mathrm{H}$. Tooth size variability and relevance of numerical variation in the Japanese serow. Arch Oral Biol 2008; 53:95-98.

10) Butler PM. Studies of the mammalian dentition. Differentiation of the postcanine dentition. Proc Zool Soc Lond, Ser B 1939; 109: $1-36$.

11) Butler PM. The prenatal development of the human first upper permanent molar. Archs Oral Biol 1967; 12:551-563.

12) Sofaer JA, Bailit HL and MacLean CJ. A developmental basis for differential tooth reduction during hominid evolution. Evolution 1971; 25:509-517.

13) Sofaer JA and MacLean CJ. Heredity and morphological variation in early and late developing human teeth of the same morphological class. Archs Oral Biol 1972; 17:811-816.

14) Gingerich PD. Size variability of the teeth in living mammals and the diagnosis of closely related sympatric fossil species. J Paleont 1974; 48:895-903.

15) Gingerich PD and Schoeninger MJ. Patterns of tooth size variability in the dentition of primates. Am J Phys Anthrop 1979; 51: 457-466.

16) Takahashi M, Kondo S, Townsend GC and Kanazawa E. Variability in cusp size of human maxillary molars, with particular reference to the hypocone. Archs Oral Biol 2007; 52:1146-1154.

17) Lanyon JM and Sanson GD. Koala (Phascolarctos cinereus) dentition and nutrition. I. Morphology and occlusion of cheekteeth. J Zool Lond(A) 1986; 209:155-168.

18) Young WG and Robson SK. Jaw movements from microwear on the molar teeth of the koala Phascolarctos cinereus, J Zool Lond. 1987; 213:51-61.

19) Fujita T. On the reduction index. Acta Anat Nippon 1950; 25:196 (Abstract, in Japanese).

20) Bolk L. Supernumerary teeth in the molar region in man. Dent Cosmos 1914; 56:154-167.

21) Fujita T. Evolution of mammalian teeth with special reference to the human dentition. Acta Anat Nippon 1958; 33:89-94.

22) Blanshard WH. Growth and development of the koala from birth to weaning. In: Lee AK, Handasyde KA and Sanson GD eds, Biology of the koala, Chipping Norton, NSW, Surrey Beatty \& Sons Pty Lmt, 1991; 193-202.

23) Martin RW. Age-specific fertility in three populations of the koala, Phascolarctos cinereus Goldfuss, in Victoria. Aust Wildl Res 1981; 8:275-283.

24) Macho GA and Moggi-Cecchi J. Reduction of maxillary molars in Homo sapiens sapiens: A different perspective. Am J Phys Anthrop 1992; 87:151-159. 